" of the uncertainties, difficulties, and dangers inseparable from the ovarian operation, I went carefully over the whole ground, and came to the conclusion that the prospect of success is, on the whole, proportioned to the fluidity of the tumour; and this prospect in the most favourable cases is about two to one." (The italics are mine.)

The inherent dangers of the operation go on increasing all through. An incision seven inches long laying open to that extent the abdominal cavity, an unavoidably violent disturbance of parts never intended to be touched, carry with them their own rate of mortality quite independent of the operator.

Provided, as Dr. Humphry would say, the tumour be of a promising character, bungling to a considerable extent would not appear to enhance nuch, if at all, the dangers of the operation. Thus I have twice seen the hand of the operator violently engaged for several minutes in the sheath of the rectus muscle. I have often seen the peritoneum mistaken for the outer wall of the cyst. In short, I have again and again wit. nessed the most signal mistakes, but never once could fairly attribute to them (excepting some to be mentioned presently) the fatal issue. All the cases above concerned recovered.

The fatal mistakes of the operator, those which make him guilty of the death of the patient, are: leaving important bloodvessels unsecured; tearing any of the abdominal viscera inadvertently, or in coarse haste to get through adhesions ; uniting so badly the external wound that it opens and lets out the intestines; treating the gravid uterus as if it were an ovarian cyst ; leaving blood or escaped fluids (even instruments, sponges, \&c.) in the cavity of the abdomen, as is so likely to happen when the operation is hurried to a close, the intestines shovelled back, and the external wound badly adjusted under that precipitate dread of peritoneal exposure which is inculcated almost within the first week of dissecting-room life.

The position of ovariotomy amongst surgical operations is avowedly grounded on its statistics. In no other department of surgery have statistics been so prominently invoked; yet, surely, nowhere else are statistics so unsatisfactory and incon. clusive. Dr. Clay laments this emphatically in his introduction to his translation of Kiwisch. He has again commenced circulating his elaborate schedules; but if operators decline to report their cases in the usual and (medical advancement considered) the only useful way, Dr. Clay will only meet with renewed disappointment. Each operator has his statistical peculiarities. Dr. Bird declined to answer Dr. Clay's inquiries in any way. Mr. Wells, up to the end of 1862 , reported every case-hospital and private; since then he has only reported his hospital cases, leaving 31 cases of his great total of 100 cases he recently spoke of in the Association Journal unsubstantiated by any report whatever.

The custom with systematic writers appears to be to accept the mere enumeration furnished by each operator, instead of exacting a detailed report, to add up the numbers, divide by the total results (also given in this profitless way), and adopt the new result as an average!

But how is it that A's deaths are 2 in $10, B^{\prime} s 3$ in $10, C^{\prime}$ 's 4 in $\mathrm{i} 0$, D's 5 in 10 ? Mr. Brown is the only operator who helps us to answer this question. As soon as he commenced selecting his cases, his death-rate fell from more than half to 35 per cent.; but on reducing his death-rate, Mr. Brown had to reject 28 per cent. as too dangerous for the operation (THE LANCET, Jan. 30th). "It is to be remarked," says Dr. Hewitt, "that such restrictions are very much to the purpose if success alone has to be considered; but then in this way is shut out from many a patient her only chance of cure." The consequence of this, which I would agree with Dr. Hewitt in regarding as a very questionable principle, has been still more strikingly exemplified at the Samaritan Hospital. The total number of ovarian cases admitted (hospital book) from 1861 to 1864 inclusive was 88 -viz., 43 ovariotomy, 27 tapping, 18 nothing done. The death-rate was 27 per cent.; but the number rejected was above 50 per cent., -more than 5 out of 10 , - whom it was necessary to consign to hopeless misery, most of them to certain death, and this too at no very remote period, to gain this small reduction in the deaths.

I have been for years engaged in ovarian investigation; but my only intention in troubling you on this occasion has been, first, to show wherein I thought your correspondent wrong in his opinions, and to justify the course taken by the lay authorities of the hospital with which we are both connected. He seems to wish to lay down a fixed principle worthy only of the gold-headed cane period-viz., that it should be the special business of some " physician proper" to decide first in any given case whether or no the ovarian operation should be performed at all; sinking, in fact, the surgeon to the level of a bone. setter. A mere operator, in my opinion, is as great a curse to an hospital as such a functionary has over and over again proved himself to be to the community. Be this as it may, the governors of the Samaritan Hospital felt it was their special business to develop the objects of the charity without regard to individual reputations or notoriets, and having carefully considered the subject of ovariotomy in the above points of view, left it to be performed, not by one only, but by all the medical officers for in-patients (excluding, of course, the "physician proper"), provided they possessed the usual surgical qualifications. You have emphatically pronounced that they wero right, and I venture to believe that every dispassionate person will think so too.

Perhaps I may be allowed to add that, all the foregoing circumstances duly taken into account, the death-rate, as asserted by Dr. West, is not diminishing ; certainly not, judging by the records in the Samaritan Hospital. But can any diminution be expected when the chief dangers of the operation depend so little upon the operator, and the issue so much upon the character of the disease?

I remain, Sir, your obedient servant,

Henry Savage, M.D. Lond., F.R.C.S. Eng, Senior Medical Officer to the Samaritan Hospital.

Samaritan Hospital, Aug. 15th, 1864.

\section{THE BRITISH MEDICAL ASSOCIATION AND ITS JOURNAL.}

To the Editor of THE LANCET.

SIR, - - I was pleased to find that some old member of the British Medical Association (under the name of "Yorkshire") still took an interest in the welfare of the Society sufficient to express his opinion with regard to the publication of the Journal.

By an unfortunate accident, I was prevented from attending the anniversary lately held at Cambridge; otherwise I should have taken an opportunity of expressing my opinions with regard to the advisability of giving up the Journal, and of substituting for it an annual volume of Transactions.

I know a large number of members of the British Medical Association who agree with me in considering the Journal as a very inferior one when compared with others. I believe that there will hardly be a dissentient voice throughout the Association on this point. Now I do not think it consistent with the dignity of such an influential Society as our own, to issue a publication which is certainly not acceptable to a large proportion of its members. My own reasons for the substitution of an annual volume of Transactions for the weekly periodical are the following:-First: We do not require a medical news journal, private enterprise supplying us with this desideratum. Secondly: We do require, as a scientific body, that our Trans. actions should be recorded in a manner calculated to render them fit companions on the shelves of our libraries for those which periodically emanate from other sister Societies.

We cannot ignore the fact that the great bugbear of our Society is the Journal. It absorbs a large income which might be devoted to the original noble object of the Society-the advancement of science by recording the efforts of its associates. The sum of $£ 272814 s, 4 d$. was last year expended in publishing a weekly paper, which finds no favour out of our ranks, and very little within them, simply from the fact that it is not a true representative of the intellect which the Society itself embodies; leaving the insignificant balance of $£ 2565$ s. $11 d$. to meet all the other expenses of the Association.

I myself joined the Association for the sake of being able to meet once a month the many talented and hard-working mem. bers of the Bath and Bristol branch-to hear their papers, and profit by the discussions evoked. For this privilege, which I do enjoy, I pay only half-a-crown a year; but I find that for the other privilege, that of reading the Journal, I pay a guinea : and all I can say is, that I would willingly relinquish the latter and pay the higher sum for the enjoyment of the former.

I hope that before another anniversary takes place this question will be finally settled, and that the votes of the Association will be taken by proxy. We all know how difficult a matter it is for medical men to attend meetings at a distance from. home, and $I$ therefore think that every associate should have a 
chance of recording his vote upon a subject which is of such vital importance to the welfare of an Association which ought to rank second to none in Great Britain.

I am, Sir, yours obediently,

ALFRED HAVILAND, M.R.C.S.,

Aug. 17th, 1864

\section{THE PROVIDENT FUND OF THE BRITISH} MEDICAL ASSOCIATION.

To the Editor of THE L AN CET.

SIR, - I have very carefully read the account of the meeting of the British MedicalAssociation at Cambridge. No part of the proceedings has been more interesting to me than the report of the committee respecting the Provident Fund. I think, Sir, an error has been committed in excluding members of the above fund over sixty years of age (who may, perhaps, have contributed to it for years) from participating in its privileges in time of sickness. I am medical officer to several clubs, also a member of two, and as far as my experience goes it is the younger members who drag most on the funds. This is the rule; there are of course exceptions to it. Please notice this, and draw the attention of the profession to it. And I suggest that if the funds be not sufficient to allow the weekly pay to the old members, why not institute some sort of extra annual contribution, to be commenced at some stated age, to allow of such provision being made for members in the decline of life? I am, Sir, yours truly,

Willingham, August, 1864. J. C. B. Smallman, M.D.

\section{THE AUTOPSY OF COOPER, THE GUARDSMAN. \\ To the Editor of THE LANCET.}

SrR,-I much regret not being able to give you an account of the post-mortem examination of the body of Private Thomas Cooper, as unfortunately I could not procure a copy of the notes taken at the examination. I was present at the adjourned inquest on Monday last, but no further medical evidence was asked for. I have sketched on wood a representation of the bullet, which I have seen, as it appeared when taken out of the chest, with the mushroom-like expansion of its apex. The bullet had passed through the paper and four inches of wood behind. I have also sketched an Enfield bullet which has not been discharged, for the purpose of comparison.

I remain, Sir, yours obediently, JohN G. WestrmacotT, M.D.

St. Mary's-terrace, Paddington, Aug. 1864.

P.S.-I have just received a note from Surg.-Major Wyatt, requesting me not to publish the sketch of the missile.

\section{THE TRAVELS OF A BULLET.}

\section{To the Editor of THE LANCET.}

SIR,-At this time, when public attention is so much directed to the fate of the poor guardsman, Cooper, the following statement may not be unacceptable, and perhaps may induce some one of the medical profession in Dublin who is in possession of notes of the case to give it in extenso.

About thirty years ago, one of the sons of the late Dr. Cheyne, of Dublin, whilst visiting an estate of his father's in the interior of Ireland, was shot; but whether by design or accident $I$ cannot remember. The bullet entered either the cavity of the chest or abdomen. The principal surgeons of the metropolis hurried down to render aid, but the ball was not extracted. At length the patient was brought up to Dublin, and both Sir P. Crampton and Mr. Cusack used their utmost efforts to discover and remove it, without effect. After some time be recovered, and for several years went about as well as ever he was, when suddenly he was attacked with symptoms of stone, which was found, on sounding, to be of large size. I cannot say which of the above gentlemen operated, but the stone was removed by one of them, the nucleus of which proved to be a leaden bullet. And Mr. Cheyne may, for all that I know, be in the full enjoyment at the present moment of sound health and spirits. - I am, Sir, yours very respectfully,

Southwark-street, Borough, Aug. 16th, 1864.

\section{GRIEVANCES OF SURGEONS IN THE ROYAL} NAVY.

To the Editor of THE LANCET.

SiR,-A few weeks ago $I$ addressed a letter to you relative to the grievances of surgeons in the Royal Navy, and called attention to the printed circular in which those grievances are fairly and fully stated.

The Warrant of 1859 , obtained under the auspices of Sir John Pakington, gave us a rank equivalent to that of commander. Another ministry soon afterwards came in, and the Admiralty Board now set to work to undo, as far as possible, the good work of its predecessor. By a most ingenious "dodge," surgeons, who ranked relatively with commanders, were reduced (relatively) to the lower grade of lieutenant; and the gold-edged peak of their caps which they had obtained and worn for a year was replaced by a plain one of leather. The ordinary dress of a surgeon (who has not succeeded in obtaining twenty years' active service) is now exactly the same as that of an assistant-surgeon of six years' seniority. Among other classes : a master, a paymaster, or an engineer of fifteen years' seniority ("half-pay" time included) wears three gold sleeve-stripes and a gold-peaked cap. A surgeon of the same, or greater, seniority wears two gold stripes on the sleeve, and a plain leather peak to his cap. In other words, seniority in the service counts for rank and uniform in all the above classes except that of the surgeon.

These may appear small matters to outsiders, but believe me they are bitterly and deeply felt by those who have been made to suffer such injustice and such marked public indignity. I still hope that you will kindly afford the unfortunate naval surgeon some portion of your potent aid.

I am, Sir, your humble servant,

August, 1864 .

GERôN.

\section{CORONERS' INQUESTS WITHOUT MEDICAL EVIDENCE.}

\section{To the Editor of The Lancer.}

Sir,-Your correspondent, Mr. Miller, in his letter of the 27 th ult., considers it would have been better had I illustrated my remarks on Mr. Bird's method of holding inquests by stronger cases than those I published. Perhaps your correspondent is unaware that my not holding a union appointment, and not being a divisional police surgeon, makes the number of inquests that fall to my lot very few. I instanced three cases, the last of which was certainly a strong one.

My chief object in bringing the subject forward was to elicit the opinion of the profession on the subject, and, possibly, your opinion on the legality of the practice. It is my intention at some future period to publish a list of cases in which Mr. Bird has selected a medical man, not far distant from this, to perform all the post-mortem examinations in cases on which he has beld inquests. Hoping you will excuse my again trespassing on your valuable space, I remain, Sir, yours faithfully, Richard Daniell, M.B., F.R.C.S.I. (Exam.) Fulham-road, August, 1864.

\section{THE INDIAN MEDICAL SERVICE. To the Editor of THr LANCET.}

SIR,- The last mail brought out the " Reorganization of the Indian Medical Service," by which order medical officers in India are to receive the pay of their rank, but will not draw either head money or staff allowance. The majority of officers will lose money by this change, although men up to ten years' service will gain slightly. But the injustice of the manner in which the medical service is treated is this. They are given the same rate of pay as the Indian staff corps; but every staff corps officer, when employed, receives also a staff allowance. Thus a regiment under the present system will have attached to it a commandant, a second in command, and one or two doing duty as officers, with the medical man. All the former receive a staff allowance in addition to their military pay. The latter, unless an assistant-surgeon, does not. If an assistantsurgeon, he gets 150 rupees per month; under the old rules he would have received 300 rupees. Every surgeon in charge of a regiment will also lose money. Every assistant-surgeon in charge of a native cavalry regiment will lose about 100 rupees per month. 